\title{
EsFEROLOGÍA Y ONTOGENEALOGÍA: EL ESPACIO COMO CATEGORÍA TRANSHISTÓRICA
}

Los espacios por los que se dejan envolver los seres humanos tienen su propia historia: una historia, ciertamente, que todavía no ha sido contada y cuyos héroes no son eo ipso los seres humanos mismos, sino los topoi y las esferas, en función de los que florecen seres humanos y de los que se caen éstos cuando fracasa su desarrollo

Peter Sloterdijk

Esferas I

El capítulo anterior permitió mostrar las variantes del pensamiento de Sloterdijk, así como sus líneas de continuidad con el pasado. En este capítulo, de manera esquemática, se intentará leer la trilogía Esferas como una ontogenealogía de lo humano en la que el eje de reflexión es el concepto de espacio. La construcción de lo humano no depende de su racionalidad como facultad, sino de un movimiento histórico que está en continuo cambio. Sloterdijk, a diferencia de Heidegger, centra su reflexión filosófica en el concepto de espacio como eje analítico para comprender la existencia del hombre en el mundo, la cual no está determinada por su temporalidad, sino por la manera como habita dentro de un espacio que es creado por él mismo. El tiempo vendría a ser una dimensión más del espacio que ha sido creada técnicamente para sostener al hombre en el mundo. Sloterdijk considera que el tratamiento que da Heidegger al tiempo como un espacio en el que es posible el análisis de la existencia obvia la dimensión fundamental 
de los hombres como individuos que están sujetos a un vivir en un espacio. La consideración de que los hombres habitan el tiempo como espacio suprime, desde la perspectiva de Sloterdijk, cientos de años de formación de la humanidad que se escapan a dicha formación como dimensión constituyente; es decir, que eliminan todo el devenir técnico al privilegiar el momento en el cual se fue plenamente capaz de construir la historia. La propuesta de Sloterdijk bebe de muchas fuentes y trata de poner especial cuidado para la construcción de una ontología espacial en la que la esencia no es sino un devenir histórico donde se va construyendo y reconstruyendo el hombre, pincelada tras pincelada, y termina este siendo el gestor de su propia historia y esencia.

Para el pensador de Karlsruhe las técnicas de humanización no dependen de las estructuras ideológicas, sino de los modos de habitabilidad ${ }^{5}$ en el mundo. El archivo gris de la genealogía es buscado en los ímpetus, las sensaciones, las miradas y todo aquello que hace que el mundo contenga vida. En Sloterdijk existe una mutua dependencia entre historia y espacio que será explorada en las más de tres mil páginas de Esferas, donde la categoría del espacio se resignifica con el pasar del tiempo y permanece presente en los intersticios de la existencia con un movimiento que la mantiene sobre un eje transhistórico ${ }^{6}$.

El hombre es un mamífero social que recompone el espacio con su fuerza creadora y articula un escenario en el cual puede desenvolver su existencia. La metáfora usada por Sloterdijk de "esferas" responde a una construcción filosófica que antepone a la unicidad de la temporalidad la multiplicidad de los espacios. No solo reconstruye un marco de reflexión, sino que aborda una propuesta filosófica exigente en la que se hacen patentes los problemas del mundo y del hombre contemporáneo. Por esa misma razón, se ha afirmado en el primer capítulo que la trilogía Esferas puede ser leída como una ontogenealogía, en la medida que pregunta por el hoy en relación con su pasado acontecido. La exploración que ha emprendido Sloterdijk tiene como propósito rehacer el relato del hombre como mamífero social que transforma su naturaleza en un mundo técnico, susceptible a ser habitado como esfera primigenia. La anteposición de un

\footnotetext{
Habitabilidad es en Sloterdijk sinónimo de vida, de un espacio cohabitado y coanimado.

6 En este punto se puede evidenciar cómo el proyecto de Sloterdijk resuena con la construcción de una crítica de la razón histórica, que recuente la manera en la que el devenir humano ha tenido presencia dentro de la existencia. En ese sentido, la reflexión de este filósofo alemán intenta reconstruir una historia que se escape de las racionalidades canónicas e integre el proceso, las técnicas y las tecnologías que hicieron posible lo que el hombre es hoy. El espacio es una categoría analítica sobre la cual cabalga el devenir humano porque es el escenario en el cual es posible la vida misma.
} 
mundo técnico es la manifestación de la poética del mundo que construye el hombre como arrojado y desligado.

Para comprender de qué manera funciona esta ontogenealogía, se propone que el cambio de valoración en la noción de espacio es el que puede servir como plataforma de argumentación para sostener que el hombre es un producto histórico-técnico, en el que existe una transfiguración de la existencia, de acuerdo con los medios y las transformaciones del entorno natural que está enfrente como mapa original. Será analizada la triple estructura que propone Sloterdijk, con el fin de explorar cómo y bajo qué circunstancias se da un cambio en las valoraciones, y de qué manera existe una serie de relaciones de poder en las cuales luchan estas nociones de espacio que modifican los modos de comprensión del hombre mismo. El capítulo estará divido en tres secciones: en la primera se examinará el espacio-intimo o "burbuja primigenia", que hace parte de cualquier historia vital; en segundo lugar, se observará cómo con la entrada de los grandes imperios y la diversificación de la política hay una modificación de los modos de habitar en los que el hombre vive sobre un "globo"; por último, se expondrá de qué modo la sociedad contemporánea estructura su espacio diversificado bajo la aparente no-estructura y la instantaneidad de la "espuma".

\section{ESPACIO ÍNTIMO: LA ESFERA DUAL}

El primer tomo de Esferas, titulado también Burbujas, es una exploración por el espacio íntimo originario en el que el hombre viene al mundo. Su recorrido afirma que el hombre es un ser dual, que recibe toda su fuerza vital del útero primario y que persigue una vuelta a esa caverna durante toda su existencia. En el útero materno, el hombre se ve abastecido con una sustancia en la que todo su ser queda envuelto y perfectamente cálido: el líquido amniótico sostiene su existencia en un interior que está a salvo de la urgencia del afuera. Durante la estancia primigenia el hombre no carece de nada, ni siquiera es necesario para él una autodeterminación, pues su inmersión en el líquido amniótico lo sostiene y lo completa sin cuestionar la procedencia o la pertinencia a ese 
lugar (Sloterdijk, 2003, pp. 343-360). No existe en ese momento una tendencia a solventar su existencia desde el afuera; por el contrario, su existencia se ve completa y perfectamente cercada por un interior cavernoso en el que no necesita de una definición.

Toda historia humana empieza con esa inmersión en el útero, su existencia depende del juego maternal en el que la placenta es una "esfera" perfectamente climatizada donde no existe carencia. En esta primera esfera el hombre no está atado a ningún afuera, ni a una circunstancia técnica que le dé calidez, allí encuentra la posibilidad de ser un desligado en el que la existencia es ligera. Los hombres, en su primera estancia en el mundo, viven en una caverna dual en la que no hay espacio para el frío del afuera, están a salvo de la inseguridad ontológica. Pese a ello, todo embarazo tiene un destino trágico: el alumbramiento. Venir al mundo es en realidad un acontecimiento nefasto en el que el hombre empieza a sentir cómo su estancia tambalea y de qué modo su constitución ontológica es insegura adoleciendo de una rígida estructura.

La venida al mundo acontece como un lugar en el cual empieza a hacerse la historia efectiva y donde la existencia debe encontrar sentido. Con pocos segundos en el mundo, el hombre se ve empujado a una situación en la que necesita de abrigo, de un afuera que lo proteja del exterior extra-humano al que se enfrenta. Su vida deja de ser un espacio de plenitud y pasa por una sensación de ahogo, en la cual cada inhalación es tortuosa. El hombre es un ser-desligado, un desvalido cósmico en el que solo acontece el tiempo como eje, un devenir que necesita refugiarse de la sensación de ahogo que le causa el exterior agreste. Si se emprende una búsqueda histórica de las condiciones de posibilidad para la emergencia del hombre, el dato inicial es el acontecimiento de aquella primera bocanada de aire en la que todo deviene existencialmente trágico; no se puede recordar nada en el interior del útero, la emergencia de todo hombre es su aparición ante un afuera, un enfrente hostil que obliga al ahogo por sobreabundancia.

El hecho de que el hombre pueda vivir una sensación de ahogo tiene que ver con una distinción que parece trivial, en la que se anteponen dos planos de expresión: el interior y el exterior. El tránsito del hombre siempre parece un movimiento de salida, que va desde un interior cálido hacia un exterior desconocido. Existe entonces una dicotomía que demarca la manera como el hombre habita su espacio; no es lo mismo "vivir" dentro que vivir "afuera". ¿Bajo qué presupuestos aparece esa dicotomía entre lo interior y lo exterior? Para Sloterdijk, el nacimiento implica la aparición de dos planos espaciales, originarios en el hombre, en los cuales se desenvuelve toda una trama histórica determinada por la manera como se habita. El interior es un espacio cooriginario donde el hombre busca la proximidad; la intimidad es un espacio de conformación del 
sujeto desde su pertenencia a otro escenario distinto y cercano. La comunión consigo mismo requiere de una autodeterminación, según la cual se posee la posibilidad de darse a sí mismo una naturaleza, pues el interior está abastecido por una serie de creaciones técnicas que sostienen una vuelta hacia el sí mismo.

Lo que aquí se llama íntimo se refiere exclusivamente a espacios interiores divididos, compartidos, consubjetivos e inter-inteligentes, en los que participan solo grupos diádicos o multipolares y que solo puede haber en la medida en que los individuos humanos, por estrecha cercanía mutua, por incorporaciones, invasiones, cruzamientos, repliegues de uno en otro y resonancias - psicoanalíticamente también: por identificaciones-, crean esas peculiares formas de espacio como receptáculos autógenos (Sloterdijk, 2003, pp. 97-98).

Muy a pesar de lo logrado con la modernidad y de la reafirmación de la psicología contemporánea, el interior no es un espacio que se habita en la soledad total; por el contrario, la intimidad es el juego de comunión con un ser dual intersubjetivo donde la existencia se juega su papel definitivo. No puede existir un yo que se afirme solitariamente, ni siquiera puede existir un yo para sí mismo, pues el centro de todo movimiento es la conciencia de que se es alguien para otro que está enfrente. El hombre no puede comenzar una historia sin la efectiva venida al mundo desde un espacio consubjetivo. Incluso, quien considere que los hombres son animales creados por Dios habrá de comprender que el aliento divino insufla la escena en la que este aparece en el mundo:

Parece que la parte esencial de la estratagema de Dios consiste en asimilar, durante la inhalación, inmediatamente otra en contra: se podría decir sin rodeos que el llamado ser originario creador no es preexistente a la obra pneumática, sino que se genera a sí mismo sincrónicamente como íntimo en-frente de su igual (Sloterdijk, 2003, p. 47).

De la misma manera, la venida al mundo como parto sabe que su primer espacio de habitabilidad es un espacio dual donde depende íntimamente de la proximidad de ese otro que da vida: la burbuja primigenia es una esfera dual que está compuesta por múltiples focos que no tienen un centro fijo sino varios epicentros en los que se entablan las relaciones múltiples de habitabilidad. El espacio del hombre está íntimamente ligado a contenerse y verse inmerso en una dualidad que estructura un escenario real de 
habitabilidad. Un sistema de receptáculos en el cual tienen lugar las relaciones intersubjetivas entre hombres, la historia se desenvuelve en un juego de técnicas que hacen habitable el mundo desde la estructuración de lazos de proximidad.

En Esferas I se relatan algunos de esos lazos en los cuales el espacio se conforma como una "burbuja dual", cuyo eje es la intimidad consubjetiva en la que se desenvuelve el mamífero hombre. La "esfera dual”, constituida por una serie de polos que se oponen, es un intento de relatar el modo en el que los hombres cuentan su venida al mundo como una efectiva reapropiación de sí mismos, como seres desligados que han perdido un cobijo primigenio. Habrá que remitirse a un espacio presubjetivo en el que no existe una formación del yo como algo sustancial. Si se quiere observar de qué modo la relación con lo íntimo es el primer estadio de la historia humana, será imprescindible inmiscuirse en lo que Sloterdijk llama la "íntima Atlántida". Con esa metáfora se pretende hacer comprensible un acontecimiento que precede a toda historia humana y que no cuenta con un archivo gris; por el contrario, lo que expone es la fuerza creadora del hombre para darse un comienzo efectivo a través del relato y de la promesa del mundo. El nacimiento es aquel evento trágico en el que la existencia tiene lugar, en el que una fuerza se hace patente trayendo consigo a alguien nuevo al mundo. Sin embargo, con la venida al mundo existe un hundimiento, el recuerdo queda ensombrecido por la carencia de palabra, por la inexistencia de un medio efectivo para la realización de un archivo que hable y relate cómo se vive en ese primer momento. Todo aquel que viene al mundo viene como un desligado, como alguien que sale de una caverna interior y se enfrenta al exterior extrahumano, y se ve desprotegido e inmerso en un lugar. "El ser-en-el-espacio fetal se describe mejor por un flotar disuelto [...] que mediante discursos" (Sloterdijk, 2003, p. 291). Ese flotar consiste en comprender la imposibilidad de la palabra y en pensar que todo espacio íntimo carece de una comprensión originaria mediante el lenguaje; cuando se está inmerso en el espacio dual, solo se puede estar en medio de sensaciones sonoras y de un espacio acústico que envuelve la existencia.

La primera estancia de todo hombre está expuesta a una serie de experimentos sonoros en los que se reconoce en un lugar. Quien es hombre debe vivir bajo una estructura que le empuja a asentar el oído en busca de ese agujero en el que la palabra no tiene nada que decir. La burbuja dual es un experimento sonoro en el que el hombre se reconoce a sí mismo como desligado y como cohabitante de un espacio en el que él mismo no es sino una parte más. 
Las voces crean campanas acústicas que se propagan esférica y actualmente, y el único modo de participar en presencias vocales solo puede describirse como un ser-en, o estar-en, en la sonoesfera actual, también el cordón umbilical tiene, como el físico, estructura nobjetiva. Cuando la madre y el hijo intercambian misivas vocales en un juego directo de ternura, su relación recíproca es la perfecta autorrealización de una esfera bipolar íntima-acústica (Sloterdijk, 2003, p. 276).

La experimentación sonora en la cueva cavernosa de la madre es la primera sensación de inmersión en la vitalidad; no ha aparecido aun el lenguaje y ya se está profundamente vivo en medio de un espacio consubjetivo cuyo eje está inserto en la relación de un par que se anima mutuamente. El hombre pertenece a un ser-en, un espacio cohabitable en el que su existencia se manifiesta por primera vez. La sonoesfera primigenia inaugura la creación de un espacio metafórico que es conocido como interior. Sin embargo, la denominación de lo interior solo puede aparecer cuando existe un exterior que le sirve de correlato y de confrontación. No existe una dicotomía entre lo interior y lo exterior, sino una relación de pares que se sustenta en un plano inmanente en el que las relaciones entre sujetos hablan de lo que está dentro y fuera. Las relaciones espaciales dependen de la articulación esférica que los sujetos entablan en su devenir histórico en conformidad con sus creencias, creaciones y experiencias.

Vivir en "esferas" es el acontecimiento primario de todo hombre, porque allí adopta una manera de enfrentar la vida; esto quiere decir que asume su existencia como un experimento en el que transforma lo dado en un medio ambiente que responde a sus necesidades y sus circunstancias. La tesis de Gehlen, del hombre como un ser activo, se reafirma en Sloterdijk concibiendo al hombre como un ser creador y transformador del espacio; mediante la técnica el hombre hace del afuera un espacio cálido y abrigado que salvaguarda la vida humana con la seguridad ontológica del estar. La geometría vital de Sloterdijk pretende sostener el mundo y explorar aquellos acontecimientos de creacióndestrucción de las esferas en el mapa exterior de la historia humana.

Bajo esa consideración, la ontología espacial de Sloterdijk posee dos dimensiones: ser-con y ser-en. El ser-en corresponde a una disposición originaria en la que los hombres se desarrollan como habitantes de un lugar: se trata de verse inmerso en medio de un espacio que es coperteneciente a la estructura ontológica, se llega a ser en tanto que se hace parte de un exterior o un interior. Venir al mundo significa tener que habitar, que crear y llenar de sentido desde la experiencia de estar en un lugar. Esta particular ontología de lo humano reside en dos presupuestos de lectura que acompañan 
la gigante empresa de una poética del espacio ${ }^{7}$. En primera medida, el hombre es considerado como un ser carente de principio y, en segunda medida, como un ser medial que vive acompasado e inmerso en una serie de espacios donde desarrolla y despliega su existencia. Para Sloterdijk el hombre vive en-medio-de, es decir, se ve disuelto y fluctuante en un ambiente coperteneciente a un exterior que le sobrepasa. La figura metafórica de Sloterdijk adquiere sentido en la medida en que expresa esa inmersión dentro de un lugar en el que no existe un centro y un límite centrífugo, pues las esferas contienen a los hombres sobre el límite de un exterior que les sobrepasa. La esfera dual es una expresión del complejo esferológico de Sloterdijk que indaga por dónde se ubica y está presente el hombre en el primer estadio de la vida animada.

"Ser-en significa ahora tanto como: dejarse abrazar, in-fluir, alimentar y animar por el medio-sangre divino, y meditar y celebrar agradecidamente ese abrazo-influjoalimento-ánimo como protoescena para devenir uno mismo" (Sloterdijk, 2003, p. 519). Así pues, para Sloterdijk esa primera escena del ser-en sostiene al hombre en un interior cálido, resguardado del mundo exterior, estructurando un primer peldaño de vitalidad con el cual el hombre se enfrentará a lo abierto. La esfera dual, como esfera primigenia, es el sostén de la primera vida animada en la que la sobreabundancia gesta una serie de repercusiones de inseguridad ontológica. El hombre enfrenta a la necesidad de asimilarse como un ser desorientado que necesita del trazo de una geometría vital común. El hombre no solo es un ser espacial, un ser-en, sino que es un ser que vive en junto con los otros. La conjunción en el espacio es el segundo rasgo radical de la ontología espacial de Sloterdijk, que consiste en dar cuenta de que el hombre es un ser-con, que vive junto al otro: "Vivimos como trabados uno en otro, en el país Nosotros" (Sloterdijk, 2003, p. 57).

El primero de los rasgos de la ontología espacial consiste en el desarrollo de una teoría geométrica vital que explora el espacio como un escenario que deslinda las cercas del yo moderno, es decir, que traba una profunda problematización del interior solipsista para apostar por una creación del espacio como escena que está abierta a la inmensidad, a lo exterior. Es por ello que una reflexión sobre la proximidad resulta determinante, en tanto que desbroza y expone la autenticidad de ocupar un lugar. Ser-en significa estar ocupando un lugar, aún sin poseer la facultad de dar sentido por medio del lenguaje y la

Es evidente que Sloterdijk es heredero de la problematización del espacio hecha por el filósofo francés Gaston Bachelard. De igual manera, el alemán se inmiscuye en el tema del espacio de un modo más complejo entablando una serie de relaciones con Nietzsche, Heidegger, Pascal, Santo Tomás y Thomas Macho. Todo esto se podrá ver expresamente desarrollado en el primer tomo de Esferas. 
palabra. A pesar de que el neonato carece de la posibilidad de abrazar su espacio con el sentido del lenguaje, no deja de experienciar su "en" y este, a su vez, no deja de pertenecer a su historia vital. Los hombres nacen en el agujero de la falta de palabra, pero viven inmersos en un espacio tangible y en una historia posible que los determina.

El ser-en-el-mundo del que hablaba Heidegger no es tematizado como algo dado de antemano ni como el advenimiento de la caída, sino como un acontecimiento histórico que contiene al hombre como un ser originariamente dual. La esferología de Sloterdijk responde a la manera como se conforman esos espacios anímicos intrasubjetivos y consubjetivos en los que el hombre se desenvuelve, sin dar por sentado de antemano una esencia universal en los hombres. Así las cosas, el salto ontogenealógico se desarrolla a merced de una exploración de la conformación esférica, de la instauración de una serie de relaciones de habitabilidad que el hombre gesta con su venida al mundo.

Esta primera argumentación de Sloterdijk aparece como un escenario de crítica a la modernidad logocéntrica, que considera al hombre como un ser unitario cuya afirmación depende de la aceptación de una esencia universal marcada por la razón y la palabra. De esta manera, es posible comprender que el hombre es un devenir histórico, que mediante la transformación del espacio modifica su estancia en conformidad con sus alcances técnicos. La violencia del exterior será determinante para acabar con la frágil esfera dual, que bajo la forma de una burbuja es susceptible de reventar en cualquier momento y bajo cualquier circunstancia. Los espacios se ven constantemente relacionados entre sí y son insostenibles cuando las percepciones que el hombre tiene sufren una variación. La esfera dual es el modo más frágil de la forma-esfera, tiende a estallar con facilidad y hace así que su habitante caiga en un mundo exterior vacío y olvide la idea de cobijo consubjetivo. El ser-con originario sufre del atentado violento del serpara o ser-parte que la historia crea. El primer estadio de reflexión esférica, que también puede ser llamado paleontología, se ve abolido con la irrupción del humanismo, en el cual el espacio es una esfera uno-todo que violenta la multipolaridad, apostando por las fuerzas centrífugas del poder. La era de las burbujas caduca en el momento en el que el hombre adquiere razón y lenguaje, y su vida ya no depende de las alianzas sonoesféricas ni del flujo de la sangre que emana del corazón por el aire, sino de la estructuración de un saber seguro, de un plano de trascendencia en el que el hombre se asienta sobre un globo redondo. El humanismo como un centro bien redondo, como la verdad noparmenídea del ser. 


\section{HUMANISMO ${ }^{8}$ Y EL UNO-TODO: GLOBOS}

Después del recorrido emprendido en el primer volumen de Esferas por la intimidad y la proximidad, Sloterdijk se inmiscuye en una empresa de mayor envergadura donde se propone examinar una serie de relaciones que modifican la estancia natural del hombre en el afuera. La ruptura del lugar primigenio es el abandono en la inmensidad de lo exterior, la exposición a un espacio que se presenta como ajeno a la esfera dual primigenia. En esta segunda pieza del relato antropodiceaco, la inmensidad abraza la noción del todo como explicación del fenómeno de la sobreabundancia del espacio y limita las constantes por medio de la violencia de la pertenencia. De ahora en adelante, los hombres no son seres mediales copertenecientes, sino partes de un todo simbólico y técnico que los salvaguarda de la inseguridad ontológica con la estructura del uno-todo inmenso. La copertenencia a un lugar se ve violentada por un espacio de fuerzas centrífugas en el que los sujetos se determinan con relación a una idea que los concentra y reparte. El advenimiento de las organizaciones políticas y de la razón contrae la inmensidad del espacio en el círculo bien redondo que se asemeja a la identidad de la esfera totalizante, cuyo centro desborda los planos de la inmanencia. El relato de la burbuja se ve sometido por la fuerza y convicción que retrae el espacio en una geometría de lo inmenso donde el mundo es redondo y total.

El segundo tomo de Esferas relata la manera como el espacio adquiere una característica circular en la que se ve cercado por el límite de la unidad concéntrica. La esfera se asemeja a una construcción de tipo cerrado, en la que existe un centro equidistante, cuyo eje concentra a los sujetos y los designa como parte absoluta: "El mundo se ha hecho aquí concepto: su ser es desde ahora espacialización del espacio, conformación de la forma, configuración de la figura, medición de la medida" (Sloterdijk, 2004, p. 23). E1 hombre deja de ser un ser-con y se convierte en un ser-parte, en el que su espacio queda definido por la idea de una globalidad que lo sobrepasa. Si el yo se mostraba como

8 Se entiende acá por humanismo el advenimiento del hombre en las altas civilizaciones antiguas donde las ideas políticas y la organización social demarcaban la manera como el hombre se enfrenta al afuera, contraponiendo esta idea a la emergencia del movimiento humanista de los siglos XIV y XV de la Italia renacentista (Sloterdijk, 2004, pp. 756-759). 
una limitante en el proceso de comprensión de la burbuja como esfera primigenia, aquí es factible comprenderlo como una modificación de ese espacio originario que hace caduca la idea de la dualidad primera. El yo no sería otra cosa que una invención técnica en la que es posible buscar un autorreconocimiento; con la modernidad se acentúa la fuerza concéntrica en la que el espacio inmenso queda cercado por la auto-referencia. Los globos son cercas que funcionan inmunológicamente y cobijan así la existencia del hombre que ha sido violentada con la pérdida, inmersión y desaparición de la "íntima Atlántida”. El globo hace estallar las esferas primigenias y reemplaza su estructura con un círculo bien cerrado en el que el hombre se siente contenido. La imagen del mundo ya no está determinada por la cercanía y la proximidad del íntimo par-originario, sino que está caracterizada por la lejanía, la inmensidad y la pertenencia a un centro. El espacio pasa a ser una atmosfera inmensa en la que los hombres están contenidos como cohabitantes lejanos. Así como en la primera esfera la calidez y la cercanía eran constitutivas, en el globo, la lejanía, el ahogo y el frío exterior son constitutivos de la ontología espacial. Con la aparición de la idea de pertenencia a un exterior aparece la práctica de vivir-con-otro, de ser-parte, cohabitante de un exterior en el que lo ontológico deviene de la mano de una construcción técnica y metafórica.

Lo inmenso es la aparición de un mundo ajeno, la inmersión en un exterior frío cuyo espacio está deshabitado y necesita de una solidez técnica. Al igual que Gehlen, Sloterdijk argumenta que después del nacimiento el hombre empieza un histórico y titánico encuentro con la técnica que le sirve para su realización. La esencia como concepto que desenmascara el fundamento de las cosas mismas no es sino una construcción técnica que guarece la existencia como un "dispositivo inmunológico". Si bien es cierto que el hombre adquiere su estatuto siendo habitante de la primera esfera-dual, es solo con la emergencia de la metafísica como se alza efectivamente sobre la naturaleza exterior para argüir su diferencia con lo otro-extrahumano. Los globos son entonces grandes relatos técnicos en los que el hombre salvaguarda su existencia de una naturaleza que es agreste y supera su temple anímico; de esa manera, los hombres heredan del exterior la idea de inmensidad y crean una serie de regazos simbólicos que reemplazan la calidez física del útero primario.

9 Esta categoría será retomada en los estudios de Roberto Esposito, quien ha hecho una cuidadosa lectura del tomo III de la trilogía Esferas. Para ampliar véase: Esposito, R. (2005). Inmunitas: protección y negación de la vida. Buenos Aires: Amorrortu. 
El ejercicio esferológico funciona como una demarcación de esos espacios redondos y artificiales que el hombre crea durante el transcurso de la historia. Así pues, se trata de comprender de qué manera los espacios demarcados configuran la existencia humana y modifican la manera como el hombre es concebido. El relato del humanismo proviene de la comprensión del espacio exterior como idea total: los globos son esferas únicas en las que el poder se desplaza hacia un centro uniforme en el que el movimiento es centrífugo. Este modo de concebir el poder es la manifestación de la metafísica por excelencia:

Por eso la imagen suprema, la sphaira, es más que un signo arbitrario que signifique el mundo. No solo es apropiada en sentido máximo al original: atrae, además, al observador, introduciéndolo en lo representado. Dado que, en tanto informa y envuelve al observador, comienza a vivir en él como idea efectiva, la esfera se manifiesta como el auténtico icono dinámico de lo existente. Lleva al ojo humano a una posición excéntrica que parece solo podría corresponder a un Dios separado; diviniza, en consecuencia, al intelecto humano que ha comprendido las reglas de la producción de la esfera. Así dado que según su dinámica interna introduce y finaliza el tránsito de la intuición sensible a la representación intelectual, la sphaira puede designarse como la figura metafísica par exellence (Sloterdijk, 2004, p. 73).

Con la caída en lo inmenso el hombre parece desorientado y cree que la esfera está delante de él, expuesta para ser concebida por su pensamiento sobre la totalidad, pero su ingenuidad es apenas explicable, pues él no está fuera de la esfera sino contenido en ella. Lo interior y lo exterior nuevamente aparecen en una tensión dialéctica de pares en la que se animan mutuamente. "Somos los contenidos por la esfera, estamos comprendidos en el anillo del ser, no estamos ausentes del todo, aunque en principio sucumbamos en la ilusión de estar en frente a la sphaira como independientes de ella" (Sloterdijk, 2004, p. 25). Los caídos en el mundo viven inmersos en lo grande y sostienen su aparición con la creación de una multiplicidad de mundos interiores que brindan calidez y cercanía por medio de la técnica.

¿Qué tienen de malo algunas creaciones técnicas, algunos resguardos cavernosos que, como invernaderos, sostienen la existencia en un lugar seguro? Es evidente que nada; lo conflictivo de la estructura del globo reside en una hegemonía de lo grande, en una violencia de lo redondo como algo absoluto que cerca lo múltiple en función de lo 
seguro. Así pues, los hombres aseguran su existencia siendo-parte, perteneciendo a un lugar, asentándose con la vista y con la sensación de pertenencia a un espacio común; la geometría demarca, delimita, dibuja líneas que no podrán sobrepasarse. "La globalización comienza como geometrización de lo inconmensurable” (Sloterdijk, 2004, p. 43). Los globos nacen como la efectiva organización del espacio de la metafísica, como el desarrollo de la idea de unidad que cree en la circularidad como manifestación de la perfección y de la identidad de todas las cosas existentes.

El relato de lo "uno" es la exposición de lo que genera la vastedad del espacio exterior a la que es expuesto el animal humano con la tragedia del nacimiento. El hombre es desde ahora un animal humano, un homo bumanus como diría Heidegger, a quien le pertenece una esencia redonda y esférica que es producto de una representación. Sloterdijk mira detenidamente las cosas y argumenta que la globalización, entiéndase aquí como el proceso de la construcción del globo, empieza con la fecundación de la idea de totalidad, que nace de la contemplación de lo alto, de la entrega al extenso y vasto campo del cielo inconmensurable, de la meditación y la entrega a la perfección del pensamiento, de la concentración taciturna. La filosofía nace como un ejercicio de contemplación de la esfera como centro redondo e inmenso, en el que el entendimiento humano captura la imagen de la perfección y conceptualiza lo que parece inconmensurable: "filósofo es quien, como atleta de la totalidad, carga con el peso del mundo. La esencia de la filosofía como forma de vida es filoponía, amistad con la totalidad de las cosas sublimes y pesadas. El amor a la sabiduría y el amor al peso de lo Uno, de la totalidad, vienen a ser lo mismo" (Sloterdijk, 2004, p. 63).

La idea del humanismo es entonces paralela al nacimiento de la filosofía, pues es con esta que la visión del hombre queda cercada por la inmensidad del concepto. El análisis que Sloterdijk elabora de El mosaico de los filósofos de Torre de Annunziata expone que con el nacimiento de la filosofía también aparece una especie de imperio del concepto (Sloterdijk, 2004, pp. 23-30). La visión parmenidea se expande hasta la incomprensión y termina por anunciar una hegemonía de lo esférico como representación de la totalidad. Sin embargo, la visión parmenidea del ser queda indeterminada incluso para sostener que con ese planteamiento nace la hegemonía de lo transcendente. Por el contrario, Sloterdijk ve en Parménides el desarrollo de una esferología de lo inmanente en la que el centro se irradia desde sí mismo, la esfera del ser se concentra desde sí misma y se determina desde la inmersión; lo concéntrico se expone como una fuerza en la que se determina el ser. El problema aparece cuando la mirada del ser se ubica desde un afuera y objetiva esa totalidad existente. Con la aparición del filósofo 
como sujeto taciturno que eleva su mirada, se crea una visión de la esfera como algo total que se separa del sujeto, lo cual conlleva a que la desviación de la mirada sea una asunción hacia lo esférico como algo perfecto, que está distanciado porque no comparte la imperfección.

La macroesferología es el relato de la conformación de aquellos úteros técnicos que se reúnen en un centro-uno: "La visión de la sphaira como imago de la totalidad seduce al vidente para que aparte la mirada o prescinda, en principio o para siempre, de su auténtico lugar en lo existente y se introduzca en una vida ficticia de espectador más allá del mundo" (Sloterdijk, 2004, p. 75). Es aquí donde es más evidente la conformación metafórica y la aparición de un espacio simbólico que juega el papel de útero segundo. El mundo adquiere sentido en la medida en que el espacio cambia de valoración, el hombre deja de ser un ser-dual, un ser-con para convertirse en un ser-parte. Quien entra en el círculo macroesferológico responderá a una serie de maneras de ver y hacer el mundo, conformará parte con otro exterior que lo sobrepasa y empezará a ser determinado por un juego simbólico de creencias construido por el lenguaje.

La geometría vital contornea los espacios por medio de técnicas simbólicas, por medio de metáforas cuyos ejes se sostienen en la creación de una serie de fuerzas centrífugas. $\mathrm{El}$ mundo es una metáfora que aparece como concepto y que se incrusta en el desarrollo de los sujetos. El humanismo, leído en clave esferológica, responde a un gran relato de constricción del espacio, a la creación de una esfera como centro unívoco que rectifica y traza las líneas del desarrollo humano: la diferencia específica demarca los límites entre la animalidad y la humanidad, y centra así el modo de comprensión del hombre a una facultad específica que le otorga un rango ontológico diferente. Los globos son la mejor manifestación de una de las tesis fuertes de Sloterdijk, según la cual la vida es cuestión de forma; si se sigue ese argumento se comprenderá que los grandes relatos no pueden ser sino configuraciones formales de experiencias radicales: donde existe la idea de unidad, existe una especie de restricción del espacio de la experiencia. La metafísica castra la multiplicidad ofreciendo un espacio de seguridad concéntrico en el que la realidad se ilumina desde un foco; las determinaciones de los globos nacen de la necesidad de contornear el caos, de darle a lo incontenible un plano de referencia en el que no se puede escapar nada. El Estado y el yo son dos ejemplos precisos de cómo funcionan los globos, pues en ambos casos la forma lo es todo (Sloterdijk, 2004, pp. 306 y ss.).

Sloterdijk desmiente aquella tesis escolar de que el humanismo es un acontecimiento que surge en el renacimiento italiano y demuestra que ese pathos vitalista, en el que el hombre es el centro de la reflexión, tiene su emergencia con la conformación 
de espacios cohabitados en las entrañas de las cavernas y su repliegue máximo aparece en la carrera atlética de los hombres por ocupar un lugar en el Estado. La megalopatia y la paleontología son dos modos de esa organización técnica en la que el poder de lo simbólico subordina el caos natural; ambas vendrían a ser técnicas de humanización y de formación de animales humanos, cuyo propósito es la producción de úteros técnicos susceptibles de ser habitados. No se trata -y esto debe quedar explícito- de una creación desde un afuera que no tiene referente, sino de una creación que el mismo hombre ha gestado desde su estado de arrojado que marca su constitución ontológica. El hombre no ha creado a Dios como un acontecimiento milagroso, ni al Estado como un agente externo, ambos son conceptos que han desbordado la esfera mundana con el propósito de cercar el espacio desde la imagen del mundo representada y pensada como exterior objetiva. Relacionada con la conformación de casas, la macroesferología se puede pensar como un escenario de crítica en el que se desvela el arraigo profundo a una serie de imágenes de mundo que se han anclado en las subjetividades. Las técnicas inmunológicas de lo grande van incrustando la idea de lo inconmensurable en todos los sujetos, y los convierte en habitantes-partes, en sujetos-máquina, en máquinas-deseantes, para usar el rico lenguaje de Foucault y Deleuze-Guattari, respectivamente ${ }^{10}$.

Siguiendo la argumentación de Sloterdijk, se podría sostener que históricamente han devenido al menos tres formas concéntricas en las cuales se manifiesta la fuerza del globo como modificación del espacio: Dios, Estado y alma. La idea de Dios como un espacio concéntrico fue propuesta por el pensador de Karlsruhe al final del primer tomo de Esferas, donde se concentró en la explicación de la aparición de un tercero consustancial que modifica la esfera primigenia: la idea de la trinidad como esfera úteroplacentaria en la que el tercero es cohabitante que se hace de la inmersión algo efectivo,

10 La idea de la globalización reconstruye y da forma al espacio metafísico, el cual ha constituido a los hombres por cerca de dos mil años de historia. La política imperial de la esfera, como política de la verdad, ha instaurado un horizonte inapelable que parece consumar la historia de la humanidad. Las tres globalizaciones ocupan largamente a Sloterdijk, quien de manera brillante logra exponer que no somos los habitantes del siglo XXI los primeros que vivimos en un mundo globalizado. La primera globalización aconteció con la expansión del concepto como figura que alcanzaba la perfección e idealización total; el eidos platónico, si se quiere, resultaba ser la cerca perfecta para una imagen del mundo que acentuaba la solidez y perfección de la forma. En segundo lugar, aparece una globalización terrestre que tiene como acontecimiento fundacional el viaje de Colon y Magallanes, a partir del cual los hombres apreciaron la solidez del mundo como esfera perfectamente redonda que gira sobre su propio eje. La transformación del mundo en una sólida esfera eliminó del panorama el plano cobijado por semiesferas que había planteado Ptolomeo; con la caída del abrigo teológico, los hombres quedan abiertos a una exploración en la que el mundo es un globo concéntrico. La tercera globalización, a la que asistimos desde hace al menos cinco décadas, consiste en la intercomunicación inteligente que ha gestado el desarrollo tecnológico de las comunicaciones a nivel mundial. Nuestro globo es hoy una especie de piel mediática en la que se transporta información a gran velocidad. 
se desplaza cuando la idea de Dios se reúne y elimina a los compartidores del espacio anímico. El aire imperial que proviene de la organización de los hombres en torno a grandes globos modifica la manera como los hombres creen habitar la esfera, pues aquí no aparecen como habitantes que comparten el espacio sino que son partes de un todo que les participa de su fuerza, que los irradia desde un punto que no es visto. Existe una metástasis de una idea que modifica las maneras de habitar de forma violenta y certera.

Bajo el manto tutelar del lenguaje, los hombres aparecen reunidos bajo un sistema de herencias, en el que comparten creencias, teorías y modos de vivir. La esferaglobo es una formación simbólica en la que la esfera burbuja pierde su volumen y se ve asimilada a una estructuración formal que se alimenta de la representación. Es el dibujo del círculo, la creación de un mapa perfectamente reconocible aquello que caracteriza al mundo como globo. El atlas moderno es la figura en la que podemos observar cómo la globalidad física es atrapada en una imagen plana del mundo: el mapa que muestra los continentes y océanos. Sobre esta afirmación es posible entender por qué Sloterdijk llama a su esferología una geometría vital donde se demarcan, miden, trazan y explican las relaciones que son gestadas en un espacio común.

Pese a que la esfera-globo sea la manifestación más perfecta y cálida creada por el hombre, esta también puede verse sometida a un estallido que deja desprotegida la existencia del hombre: la idea del uno-todo tambalea con la aparición de un ambiente enrarecido en el que las fuerzas del centro empiezan a ser menos fuertes y extrañamente de menos alcance. En nuestra sociedad contemporánea la forma de dios y, un poco menos, la del Estado quedan clausuradas porque el sujeto irradia sus fuerzas extáticamente; esto quiere decir que ya no dependen de la unidad concéntrica que se expande desde un centro, sino que cada sujeto irradia su fuerza desde sí mismo.

La proposición 'Dios ha muerto' significa en primer lugar una tragedia morfológica: la aniquilación, por una infinitización implacable, de la esfera inmunidad, intuitiva, clara, imaginariamente satisfactoria. Dios se convierte en algo invisible, oscuro, desemejante, amorfo: un monstruo para la capacidad intuitiva humana, un no-receptáculo, un abismo y agujero absoluto. De pronto, dado que ha desaparecido la barrera entre interior y exterior, ya no se puede entender en qué habría de consistir la ventaja de estar dentro de ese dios de infinitud (Sloterdijk, 2004, p. 117). 
Así pues, la misma proposición con la que Nietzsche confinará al espectro de Dios y la metafísica sirve para exponer la ruptura del globo como imagen del mundo que se quebranta. El espacio deja de ser un globo-imagen y se convierte en un universo contingente en el que el azar y la fuerza de gravitación son, esporádicamente, los únicos centros existentes. El globo finaliza allí donde se concreta la muerte de Dios, donde se pierden las seguridades metafísicas y se visibiliza la asolada y finita estructura ontológica del hombre. La historia que cuenta Sloterdijk intenta demostrar cómo aparece esa serie de mantos inmunológicos dentro de los cuales el hombre habita, el tejido metafórico sirve como escenario de transformación del hombre, como transfiguración de los topoi.

El recuento que se ha emprendido hasta acá tiene como propósito esquemático mostrar el posible cambio en la valoración del concepto de espacio que tiene lugar en el proyecto de Sloterdijk. La metáfora del inicio primigenio es superada por el relato de lo inmenso, por el acontecimiento de la pertenencia. Habitar, en este segundo tomo de Esferas, es una cuestión de pertenencia a un lugar de exposición ante lo común que se vuelve propio. El globo es la difusión de la esfera primigenia y la aceptación de la representación como técnica de agenciamiento de lo propio. En lugar de establecerse como un par-dual, el hombre busca por sus propios medios reconocerse en un exterior inmenso. Sin embargo, después de la Primera Guerra Mundial y de las catástrofes que han mostrado el evidente resquebrajo de esas viejas seguridades, Sloterdijk propondrá que:

De lo que se trata tras nuestro cansancio de los infinitismos postestructuralistas es del trabajo en una ontología del mundo finito, inacabado, inmenso, en el que hay que compensar, en sus radicalismos, momentos conservadores y explosivos, o, como también se podría decir, intereses psíquicos y técnicos. ¿Dónde estamos cuando estamos en lo inmerso? (Sloterdijk, 2004, p. 121).

Del tratamiento que se le dé a esa cuestión cambiará la manera como los hombres se comportan en el mundo. Fijar la cuestión de lo humano en los espacios se convierte en la manera de estructurar un tipo de ontología que no descuida el regazo histórico en el que indiscutiblemente se ve inmiscuido el hombre. A esa manera de estudiar el hombre es a lo que hemos llamado ontogenealogía: un estudio del hombre que intenta valorar la cuestión desde un ámbito transhistórico que queda incrustado en todos los sujetos humanos.

Para terminar este asalto del relato esferológico se pasará ahora al tomo III de la trilogía Esferas, en el que el hombre aparece constituido por un centro siempre 
descentrado donde las esferas adquieren la volatilidad y fragilidad de la espuma que de manera multitudinaria pueden agenciarse para crear un gran movimiento de coexistencia. La diversificación responde a una "espumificación" del espacio, a una atomización de la sociedad.

\section{ESPUMAS: SER-EN-MUCHOS-LUGARES}

El recorrido esferológico culmina con el desarrollo de las esferas como formas que se diversifican, que expanden la vitalidad y trastocan los conceptos de proximidad y lejanía. La era metafísica caduca con una explosión interna que la hace insostenible porque soslaya la multiplicidad con la hegemonía del todo-concéntrico de la forma globo, que confina al mundo a una imagen en la que todos los puntos existentes son conmensurables. Hablando de la metafísica, Sloterdijk dice:

en verdad, es la imposibilidad interna de su proyecto la que fue la causa de su ruina. Los pocos que se la tomaron en serio lo comprenden incluso hoy: se hace añicos porque pretende defender el asunto de la vida, que por naturaleza solo se mantiene en la finitud de un sistema de inmunidad individualizado, y toma partido, a la vez, por lo infinito, que niega toda vida individual e ignora intereses de inmunidad privados (Sloterdijk, 2009, p. 19).

Pero entonces, ¿cómo salvaguardar la vida lejos de la inconmensurabilidad del espacio? ¿Cómo limitar la apertura al mundo y alejarse de las categorizaciones de lo uno-infinito? Puede que la respuesta a estas dos cuestiones quede resuelta en el tercer y último tomo de la trilogía, en los cuales el proyecto esferológico es comprendido como una manifestación ética, estética y política en la que la vida se construye de forma limitada. En este punto, la propuesta de Sloterdijk puede ser leída bajo el horizonte de una ontología espacial de lo finito, que demarca los límites y comprende cómo la expansión de los conceptos moviliza imágenes que se hacen evidentes más allá de los referentes 
físicos. La idea de Dios, del Estado y del mundo como un globo son la evidencia más clara de la organización en la que lo simbólico se ha vuelto hegemónico, el espacio ha devenido como un receptáculo que adquiere ciertas características dadas por los hombres en tanto que habitantes del mundo.

Espumas es la propuesta filosófica más arriesgada de Sloterdijk, no solo porque concluye todo un esfuerzo de creación filosófica, sino porque es donde finalmente se evidencia la fuerza de la historia crítica. En este último tomo, el concepto de esfera ha alcanzado un profundo desarrollo filosófico que consigue exponer una lectura de la cuestión del hombre en clave genealógica, donde se diagnostica el presente y se muestra cómo una serie de formas de habitar conviven en el espacio y permanecen así sometidas a unas relaciones de poder no siempre de orden negativo. La expansión filosófica del concepto esfera tiene como consecuencia un desarrollo donde el espacio es transfigurado de acuerdo con la experiencia vital que el hombre crea en su trasegar histórico individual, plural y multifocal. Las espumas son esferas que, como sistemas inmunológicos, adquieren un rasgo finito que no sobrepasa la mirada del hombre hacia algo que va más allá del mundo.

La modernidad trajo para Sloterdijk dos condiciones de habitabilidad: por un lado, con la pérdida de un cobijo teológico-metafísico el hombre se ve expuesto a un trasegar inseguro; por otro lado, la individualización del espacio inmunológico, que consiste en el fortalecimiento de la inmunidad yo como técnica de humanización hegemónica. Ambas representan una época en la que el hombre necesita de sus propias determinaciones y de sus propios medios para desenvolver su existencia y exponerse como tal. Con la modernidad no hay ningún yo que se defina inmunitariamente desde una exterioridad que no sea él mismo. A pesar de ello, con el advenimiento de las sociedades contemporáneas, la figura del yo ha sido deconstruida y se ha mostrado que su plasticidad técnica proviene de su fuerza para determinarse a sí misma. Partir de ese centro moderno para una definición del hombre no es sino una muestra de ingenuidad filosófica, como ya hubiesen prevenido los gestores de la antropología filosófica de los años veinte y treinta en Alemania.

La forma-espuma expresa otro cambio en la valoración del espacio que consiste en la exposición del hombre a un lugar donde el centro está en todas partes. Con la implosión de la metafísica, el hombre ha quedado expuesto en un inhóspito lugar en el que su espacio se hace evidentemente finito. Cuando el globo macroesferológico ha reventado, no se puede esperar sino una apertura hacia lo abierto-finito en el horizonte de una ontología espacial. El mundo ha dejado de ser un espacio de cohabitabilidad 
irradiado desde un centro y ha pasado a ser un lugar en el que multifocalmente el hombre se expone. La tragedia del nacimiento y el desencanto del mundo han desembocado en una apertura finita de los espacios en los que el hombre ya no depende del íntimo ser-juntos, ni del exterior ser-parte. Sloterdijk comprende la complejidad de los modos de habitar de hoy manifestando que los sistemas de inmunidad actuales responden al desarrollo de hiperestructuras altamente técnicas que no pueden ser pensadas como diadas animadas por la solidaridad, ni como globos que se mueven desde un eje central y monolítico.

Sin embargo, la espuma está irremisiblemente ligada a la estructura de la esfera dual primigenia que exponíamos al principio: la fragilidad y la fuerza del estar-juntos son características que la espuma y la burbuja guardan en común. En ambas el sujeto está incrustado dentro de un espacio que necesita ser animado desde sí mismo con la fuerza de su ser-en un lugar. Debe comprenderse que esto no tiene nada que ver con la fuerza unitaria de un yo moderno solipsista, sino de una insuflación propia que acontece con la entrada del hombre a un medio, con la animación de un espacio que se abre para los hombres y su transformación. En la sociedad contemporánea el espacio sufre de una mezcla de ese plexo histórico hasta aquí expuesto, en el que las formas-esferas mutan, agencian, conviven y se destruyen. La ontogenealogía explora de qué manera la pertenencia a un lugar está cruzada por esa serie de conformaciones espaciales y cómo estas se solapan las unas a las otras, cohabitando y modificando la concepción que el hombre tiene de sí mismo y de los demás que lo rodean.

Pese a que los hombres de hoy habiten un espacio en el que existen diversas formas de habérselas con el mundo, es evidente que el espacio sufre de un resquebrajo en el que las antiguas imágenes del mundo se hacen débiles y en el que los viejos sistemas de inmunidad (Dios, alma, ciencia, Estado) parecen caducos aun cuando sus efectos de unificación y reificación sigan siendo efectivos. Con Espumas, Sloterdijk intentará mostrar que tras la metafísica monista es posible concebir el mundo como un centro siempre descentrado. El advenimiento del mundo como un exterior que no tiene centro, en el que la representación es superada por la expresión multifocal de los espacios, confina la imagen del globo a un olvido en el que es posible recuperar la multiplicidad de los espacios, que no dependen ya de un centro cerrado. La representación como manera certera de ver el mundo ha caducado como sistema inmunológico; en las sociedades de hoy el individuo no puede confiar en aquellos sistemas que reparten a los sujetos de acuerdo con un capricho formal de lo redondo, donde se elimina el volumen de las circunstancias esféricas por una representación plana. La idea del globo centrado es insostenible, si 
con ella se olvidan los espacios-otros que conforman el volumen de una esfera finita. Así pues, este último tomo de la trilogía intenta exponer la manera como está constituido el espacio contemporáneo en el que las formas-representadas se han vuelto insostenibles. Lo que argumenta Sloterdijk es que con la intervención altamente técnica el hombre ha modificado el mundo en el que incluso las imágenes se han vuelto insostenibles. En Esferas III, el autor dice:

Espumas ofrece una teoría de la época actual bajo el punto de vista de que la vida se desarrolla multifocal, multiperspectivista y heterárquicamente. Su punto de partida reside en una definición no-metafísica y no-holística de la vida: su inmunización ya no puede pensarse con los medios de la simplificación ontológica, de la recapitulación en la esfera-todo-lisa (Sloterdijk, 2009, p. 23).

La vida sufre de una exposición a lo abierto que parece nada o casi nada. Las espumas son contornos finitos de lugares habitados por hombres que están sujetos a un movimiento violento y constante. En ese sentido, el espacio no estaría sometido a una dualidad ni a un centro, sino ligado a un movimiento fluctuante cuyo centro parece disolver todas las identidades fijas. La conformación de la forma-espuma tiene su emergencia después de la Primera Guerra Mundial, en la que aparece una serie de ataques que destruyen los medios en los que es posible la vida; la inseguridad ontológica ya no es provocada por la inmensidad del exterior que sobrepasa a lo humano, sino que es creada por el hombre mismo con el uso desmedido de sus avances técnicos. Si la sensación de ahogo por sobreabundancia aparecía como una de las características esenciales de la esfera primigenia y el frío cósmico justificaba el desarrollo de una política de calentamiento con la formación de esferas bien cerradas, el terrorismo contemporáneo ha generado un ambiente de inseguridad que se caracteriza por la incontenible y espantosa sensación de no poder respirar seguros. El problema del mundo contemporáneo reside en que los hombres son los gestores de esa falta de aire, de ese ambiente de inseguridad ontológica. El pensador de Karlsruhe designa a la situación actual como una época en la que el aire tiembla, donde los receptáculos han perdido la orientación y se ha enrarecido el medio ambiente. Los sistemas de inmunidad responden a una analítica de las atmósferas, un profundo estudio de la conformación de los espacios como receptáculos que cuidan a los hombres que los habitan. En Esferas III se expone un tránsito en el que el concepto esfera alcanza el rango de una analítica de la habitabilidad, donde el hombre puede crear nuevas formas y sostener aquellas que expanden su vitalidad. Justo aquí, la idea de que 
la vida es cuestión de forma adquiere un valor insuperable, pues de lo que se trata es de conformar, de rehabitar, de resignificar esas formas para crear nuevos espacios de habitabilidad en los cuales se contienen los hombres.

Las espumas son entonces las formas actuales de nuestra coexistencia, donde nos sostenemos y habitamos. La figura de la espuma evoca inmediatamente un tipo de estructura que carece de sólido fundamento, donde la pérdida y la fuga son acontecimientos formales de la vida misma. "Para la teoría, que acepta el ser-en-la-espuma como determinación primaria de la situación, super-visiones concluyentes del mundo-uno no solo resultan inaccesibles, sino imposibles, y, si se entiende bien, tampoco deseables" (Sloterdijk, 2009, p. 53). El espacio de la vida se articula en conformidad con una idea en la que el poder no tiene un eje de actuación centrífugo. La ontogenealogía empieza a mirar hacia el presente, a cartografiar los modos en los que los hombres construyen espacios técnicos, que sirven como escenas de habitabilidad común. Los espacios de hoy ya no se expresan con el panoptismo de los globos ni con la fragilidad de las burbujas, sino que son grandes complejos técnicos que crean medios ambientes de seguridad ontológica y de resguardo climático. Sin embargo, la figura de la espuma tiene unas características peculiares y su constitución depende de una profunda desestructuración en la que el espacio de la vida no queda contorneado bajo ninguna cerca. Se trata de una manera de concebir la vida, en la que no es posible comprender el movimiento fuera de las dinámicas del agenciamiento y des-agenciamiento. Los espacios de hoy ya no son solo de carácter metafórico, sino que están expuestos ante los ojos con el avance de los desarrollos técnicos; las metáforas del mundo contemporáneo se han hecho perfectamente realizables, los espacios se han construido como escenarios arquitectónicos donde el espacio es diseñado en conformidad a esas imágenes de mundo, creadas desde el agenciamiento de diversos mundos gestados por sí mismos. "Por eso la espuma constituye un interior paradójico, en el que la mayor parte de las co-burbujas circundantes son, a la vez, desde mi emplazamiento, vecinas e inaccesibles, y están, a la vez, unidas y apartadas" (Sloterdijk, 2009, p. 49). Lo humano aparece como un escenario de realización de ese interior-paradójico en el que se desenvuelven los sistemas de inmunidad, como receptáculos en los que es posible el advenimiento de los hombres que cohabitan con otros hombres.

¿Qué es entonces la forma-espuma? La espuma es considerada por Sloterdijk como la conformación esférica que describe el mundo contemporáneo, en el que nos enfrentamos a una era posmetafísica caracterizada por no poder sostener estructuras sólidas y formalmente duraderas. Pese a que los hombres de hoy no puedan vivir en 
sólidas casas globales, su existencia se mantiene dentro de ellas, pero modificada por la creación de un medio ambiente que ya no guarda correspondencia con ellas; los hombres de hoy pertenecen a largas tradiciones nacionales y a extensos territorios que se cobijan bajo un manto constitucional y una bandera que intenta capturar hasta el viento que pasa por el territorio, pero la volatilidad del mundo contemporáneo no permite sostenerse dentro de estas formaciones globales, que procuran mantener un clima perfecto por medio de técnicas de invernadero. Con lo que Sloterdijk llama atmoterrorismo devino una existencia en la que mundo es un escarpado espacio donde el ahogo no deviene por sobreabundancia, como en la burbuja, sino que aparece como un fenómeno de enrarecimiento: en épocas descascaradas, hasta respirar resulta un acto difícil:

Las relaciones de civilización técnica no consienten ya que, como en el caso del experimento de Dalí1 ${ }^{11}$, se olvide lo esencial: seres humanos, que se encuentren momentánea o habitualmente en típicas situaciones-indoors, tienen que ser conectados a un sistema de abastecimiento de aire auxiliar. La explicación avanzada de atmósferas obliga a una continua atención a la respirabilidad del aire: primero, en sentido físico, pero, después, también, y progresivamente, en relación con las dimensiones metafóricas de la respiración en espacios culturales de motivación e inquietud (Sloterdijk, 2009, p. 134).

Lo humano queda desprotegido en un ambiente físico que ya no responde a las condiciones mínimas para la supervivencia; la vida humana dejó de depender de la naturaleza primera, a tal punto que consiguió asentarse sobre el mundo humano una hegemonía de lo simbólico. Los hombres ya no habitan en una naturaleza originiaria, sino que son parte de un medio ambiente que los rodea, que comparte el espacio con otros medios-ambientes, que demarcan límites-frontera y estructuran así una multiplicidad de sistemas que coexisten simultáneamente. Sloterdijk comprende que la vida humana de hoy es un complejo espacio en el que se sostienen diversidad de medios, que compiten por hacer a los hombres de una determinada manera. Las esferas de hoy son creaciones atmosféricas, diseños de aire, espacios construidos arquitectónicamente con el propósito de hacer del afuera un espacio cómodo y consustancial al interior.

11 Sloterdijk se refiere al performance llevado a cabo por Salvador Dalí el 1 de julio de 1936 en Londres, donde pronuncia una conferencia titulada: Fantômes paranoiques autentiques. 
La existencia del hombre se ve sumergida en un espacio en el que no es considerado como alguien a quien le pertenece una esencia; por el contrario, los hombres son vistos desde un ángulo mucho más primigenio y elemental: el hombre es un ser que respira, que solo puede vivir en un lugar donde el aire no se vea enrarecido y resulte lo suficientemente sano para sostener su vida. Lo simbólico le sirve al hombre como un escenario en el que una serie de prácticas inmunológicas se agencian con el propósito de estructurar microinvernaderos de seguridad que lo contengan. Con el aire enrarecido, los hombres buscan con mayor afán estar bajo lugares en los que el aire responde a un diseño programado técnicamente, el afán por variar el clima, por crear un espacio, ya no es un mero lujo proveniente de las lecturas de ciencia ficción, sino que es un lugar físico en el cual acontecen las relaciones humanas mismas.

Los hombres de hoy se resguardan bajo una multiplicidad de espacios que cumplen con una serie de parámetros de seguridad y con unas condiciones que les hacen sentir en un espacio finito donde es posible su contención. Sloterdijk mostrará en el último libro de la trilogía cómo el espacio empieza a ser para los hombres un plano en el que es posible ser-en-muchos-lugares. Lo que había sido una geometría de lo redondo, como analítica de los globos, ahora debe ser expresado como una arquitectura de los medios. Donde se exploran los diseños, los planos, las ideas y la conformación de los mismos espacios como respuestas a unos modos de vivir específicos. La "casa del ser" ha sido derrumbada y ha empezado a ser rediseñada como una multiplicidad de espacios agenciados. El devenir de la espuma es la consolidación de un environment en el que se contraen las relaciones de vitalidad y donde los interiores son expuestos con otros en un movimiento de ida y vuelta que no desaparece, que desestructura las fuerzas centrífugas propias de imagen del mundo metafísica. Con la espuma se termina todo un retrato de la manera como los hombres se conforman y se hacen tales de acuerdo con el tratamiento que le dan al espacio que habi$\tan$. Las formas-esfera son creaciones técnicas que constituyen a los hombres, que nacen simultáneamente con ellos, que coexisten en un mismo plano, que forman espacios en los cuales estos desenvuelven su existencia. La vida de los hombres hoy depende de sus posibilidades para crear nuevos espacios de inmunidad: "Quien en la sociedad-multi-media se aventura a salir del propio acantonamiento ha de estar seguro de su equipo de inmersión, es decir, de su sistema de inmunidad tanto físico como mental, o bien, de su cápsula espacial social" (Sloterdijk, 2009, p. 129).

En ese sentido, la esferología empieza a desembocar en un arte de vivir en el que se exponen una serie de técnicas que hacen al hombre lo que es; la vida humana se conforma desde la realización de espacios inmunológicos que posibiliten la vida. De ahora 
en adelante, el "diseño de la vida" resulta determinante como medio para estar-en-elmundo, como sistema de inmunidad en el que se configuran atmósferas de habitabilidad. Si hemos quedado ante la asolada de un espacio cuyos contornos ya no provienen de un centro fijo, ¿cómo entablar relaciones de solidaridad y vitalidad? ¿No parece el mundo de hoy un escenario en el que los hombres han devenido una especie funcionalmente dividida? ¿Cómo contribuye el diagnóstico de Sloterdijk al desarrollo de lugares-otros, de nuevas creaciones metafóricas que superen el anquilosamiento de lo uno y que limiten la "aparente" fluidez sin fin de la espuma-múltiple? ¿Cómo aparece lo genealógico de la ontogenealogía? Cabe recordar que en el primer capítulo se dijo que la pregunta por el hombre se transformaba en un escenario de investigación genealógica, donde se emprendía una cartografía de los espacios, de las valoraciones de ellos y de la reconfiguración del sentido de lo humano como consecuencia de esa transfiguración espacial. Este capítulo pretendía navegar con un rumbo preciso en la trilogía de Sloterdijk, con el fin de explicar el modo en el que se hacen patentes tres grandes valoraciones del espacio que, a su vez, dan al concepto de esferas un rango filosófico. Hemos tratado de argumentar cómo existe un cambio desde la díada-dual de las burbujas, donde el hombre está caracterizado por su ser-en, pasando por el globo-todo en el que los hombres se reúnen como ser-parte, hasta llegar al múltiple escenario donde el hombre puede ser-en-muchos-lugares. En cada caso, la vida humana es una cuestión de forma, una edificación metafórica que estructura límites y diseña naturalezas segundas que se componen como atmosferas, sistemas de inmunidad y úteros técnicos donde es posible la existencia de los animales humanos. La transformación de la categoría de espacio depende entonces de esa habilidad técnica que tengan los hombres para hacer de eso que tienen afuera una esfera de habitabilidad inmunológica, el mundo humano es el producto de un cambio en la valoración del espacio que habita de manera paralela en nuestro presente.

Finalmente, en el tercer capítulo, se culminará este análisis de la obra de Sloterdijk respondiendo a las preguntas que han surgido con la lectura de este capítulo, tales como: ¿en qué desemboca la esferología propuesta por Sloterdijk? ¿Cómo se define la importancia filosófica del proyecto de Sloterdijk? ¿Qué pasa con la pregunta por el hombre leída en clave genealógica? ¿Realiza Sloterdijk una ontología crítica del presente? Además, serán retomados los elementos de los dos capítulos precedentes con el propósito de hilar una serie de problematizaciones que sirvan de conclusión al problema de la antropología filosófica como ontogenealogía. 
